\title{
'N BLIK OP DIE LEDE VAN DIE OU FAKULTEIT
}

\author{
F. J. VAN ZYL
}

1. Inleiding.

1(i). U sal seker almal met my saamstem dat die tema wat deur my gekies is om op die vyftigste verjaarsdag van „Van der Hoff" behandel te word, uitstaan tussen die ander temas vir hierdie predikantevergadering, vanweë sy eenvoudige, ongekompliseerde en onteologiese voorkoms. Ook wat dit betref is dit miskien egter goed om u vroegtydig te herinner aan ons bekende Afrikaanse spreekwoord, dat in man nie op sy baadjie getakseer moet word nie. Miskien is hierdie voordrag juis vir hierdie onmenslike uur van die dag gekies omdat die titel die belofte inhou vir 'n oomblik van toeskouersgenot waarin 'n mens sonder teologiese inspanning jou kan verlustig in ' $n$ behaaglike beeld uit die verlede. Dit spyt my om so 'n begeerlike vooruitsig meteens wreed te versteur. Maar dit is nou eenmaal so dat teoloë van 'n teologiese vereniging in 'n teologiese vergadering nie bloot toeskouers van in stuk teologiese geskiedenis uit die verlede kan wees nie. As teoloë staan ons altyd in verantwoordelikheid nie net ten opsigte van die teologie van die dag nie, maar ook van die verlede. Daar kom vrae tot ons uit die verlede waarmee ons vandag moet worstel en waarop ons vandag 'n antwoord moet gee. Soms omklem die vrees my hart dat wat Barth een keer gesê het dalk ook waar kan wees van ons kerk: dat alleen daardie teoloë wat dink dat hulle dit so wonderlik ver gebring het, nie meer wil luister na die bevinding van 'n skrander man uit die verlede nie. Om u gespanne nuuskierigheid te prikkel wil ek heel aan die begin sê dat ek by die blik op die lede van die ou fakulteit die ervaring gehad het dat hulle almal lewende vrae geword het aan ons kerk vandag sodat hierdie vyftigste gedenkjaar van „Van der Hoff" dalk vir ons 'n jaar van waarheid kan word.

1(ii). Hoewel ons op die oog af onproblematiese tema geen verduideliking of nadere bepaling van moeilike woorde en begrippe verg nie, lê daar tog 'n klein probleempie voor ons wat vooraf opgeklaar moet word. Dit gaan nl. om die vraag wat met „die ou fakulteit" bedoel word. Waar het die ou fakulteit begin en geëindig, en sedert wanneer dateer die nuwe. Soos almal weet is die fakulteit 'n paar jaar ouer as .,Van der Hoff" en kon ons sy halfeeufees reeds agt jaar gelede vier. Die teologiese opleiding het begin met die aanstelling van prof. J. H. J. A. Greyvenstein in 1916, later gevolg deur die van die bekende twee ou professore, S. P. Engelbrecht en 
B. Gemser. In die aanvangsjare, het die proff. Macmillan en Patterson ook ' $n$ aandeel gehad in die opleiding van ons predikante. 'n Nuwe bedeling het aangebreek toe die teologiese fakulteit kontraktueel gebind is aan ons kerk en 'n nuwe periode het aangebreek toe dr. H. P. Wolmarans in 1935 dosent in godsdienswetenskap geword het, en professor in 1938. 'n Mens sou ook van die ou fakulteit in ' $n$ jonger verband kon praat, toe hy benewens Engelbrecht, Gemser en Wolmarans ook beman was deur prof. A. S. Geyser, en in deeltydse hoedanigheid, deur proff. C. H. Rautenbach en A. van Selms.

1 (iii). Die ou fakulteit wat hier bedoel word is daardie een wat deur die woordjie "blik" aan die begin van die opskrif bepaal is. Nou is daar ook weer in die wêreld sowel as die kerk verskillende blikke. Daar is in beide gewone blikke en leë blikke. Om alle misverstand uit die weg te ruim is dit nodig om te verduidelik wat in die verband van ons tema onder ' $n$ leë blik verstaan moet word. Ek wil dit omskrywe as daardie historiese beeld uit die verlede wat ' $n$ mens kry deur rekonstruksie van 'n stuk lewe uitsluitlik uit geskrewe materiaal. Hulle is ontsaglik belangrik en die mees algemene. Daar is egter ook ' $n$ historiese beeld wat gegrond is in die daadwerklike belewing van hulle wat daarby gewees het as oog- en oorgetuies. Die beeld van die ou fakulteit en sy lede wat $u$ hiermee aangebied word is een wat só bepaal en gegrond is. Dis die beeld van die viermanskap Greyvenstein, Engelbrecht, Gemser en Wolmarans soos beleef in die jare 1936-1938.

1 (iv). Die lede van die ou fakulteit was soos ons almal mense van vlees en bloed. Twee van hulle is nog by ons, van wie een vandag hier onder ons verkeer. Prof. Engelbrecht, reeds in die tagtig, lê nou al etlike jare aan die bed gekluister in die hospitaal-afdeling van "Ons Tuis". Ons is dankbaar dat prof. Wolmarans, ook reeds diep in die sewentig, nog redelike goeie gesondheid geniet. Hy hou hom in sy ouderdom nog uit die kwaad deur hom besig te hou met sy groot liefde: die boerdery. Omdat hierdie vier manne, gesamelik en afsonderlik, ' $n$ belangrike rol gespeel het in die opleiding en in die kerk gedurende 'n baie groot gedeelte van die vyftig jaar wat deur die halfeeu-fees van "Van der Hoff" in herinnering geroep word, is dit goed om hulle en hul werk ook in herinnering te bring. Nou glo ek dat ons almal nie ewe veel persoonlik geïnteresseerd is in ' $n$ blik op die lede van die ou fakulteit nie. Daar is ons ouere groep predikante wat $u$ na eie beliewe maar die toplaag of die droë hout kan noem, wat waarskynlik met 'n mengsel van vreugde, weemoed en dankbaarheid saam met my ' $n$ blik in die verlede sal werp. Ons hoop dat die jongere geslag wat aan ander voete gesit het, nie so selfvoldaan sal wees dat hulle nie ook teologiese lering uit die verlede sal kan put nie. 
$1(v)$. Die bedoeling is geensins om biografiese besonderhede mee te deel nie. Ons wil volstaan met die weergawe van enkele tiperende indrukke sover dit die persoon van hierdie manne betref. Verder wil ons ook die werk van elkeen afsonderlik tipeer en veral die betekenis daarvan aandui vir hulle tyd en vir ons tyd. Maar omdat die wetenskaplike werk van iemand nooit losgemaak kan word van sy persoon nie, sal die tipering van persoon en werk inmekaar vloei. Ons wil hulle werk gaan bekyk as die werk van mense wat saam met ons aan die kerk van Jesus Christus behoort, wat in hulle tyd met vrae geworstel het en antwoorde probeer gee het en op hulle wyse getrag het om die kerk kerk te laat wees, mense wat vandag voor ons staan met vrae wat ons in 'n sekere verantwoordelikheid stel. Wat die persoonlike betref, wil ons weereens opmerk dat hulle gewone mense was. ' $n$ Mens bly ' $n$ mens, ongeag die tyd waarin hy lewe. Mense het deugde en ondeugde. Mense is sondaars. Pascal het gesê van die mens; wat ' $n$ wonder, 'n gaos, ' $n$ monster, ' $n$ maalstroom van onsekerheid en vergissing. Oor die persoon van hierdie manne wil ons geen oordeel uitspreek nie. Daaroor oordeel iemand anders as 'n mens.

\section{Teologiese inkleding van die tema.}

2(i). Ons het reeds daarop gewys dat ondanks die feit dat hierdie tema oënskynlik geen buitensporige teologiese verwagtings by ' $n$ mens opwek nie, hy tog wel deeglik betekenisvolle implikasies het. Wat dit alles inhou, moet nader aangetoon word. ' $n$ Mens sou die besig-wees met ' $n$ stuk geskiedenis van die teologie op twee maniere ' $n$ teologiese karakter kan gee. Waar dit hier om ' $n$ blik in die verlede gaan wat hoofsaaklik op persoonlike ervaring gegrond is, sou ' $n$ mens dit teologies kon kleur deur jou herinneringe in ' $n$ teologiese kader te plaas. Jou werksaamheid is dus self geen teologie nie, maar jy plaas dit in ' $n$ bepaalde teologiese omlysting. Omdat dit ons hier te doen is met die ou fakulteit, sal wat gesê wil word nie direk binne die omlysting van die huidige teologie geplaas kan word nie, maar in die kader van die 19de eeuse teologie wat met die uitsondering van een die teologie van al die lede van daardie fakulteit was. So 'n werkswyse sou nie betekenisloos wees nie. Miskien is dit goed om so hier-en-daar ' $n$ greep uit daardie teologie te maak om weer eens te ontdek hoe aktueel baie van die vrae van daardie tyd vandag nog is. ' $n$ Groot groep van ons predikante wat bevoorreg was om met die dialektiese teologie kennis te maak toe die name van Karl Barth en Emil Brunner helder en wyd soos ' $n$ sweepklap oor die teologiese veld geklink het, weet dat ' $n$ mens hierdie teoloë nie goed kan verstaan as die agtergrond van die 19de eeu met sy Lessing, Kant, Hegel, Schleiermacher, Troeltsch en Ritschl ontbreek. Die jongste geslag van predikante weet miskien te min van hierdie manne, wat dit ook weer moeilik maak om die 
nuwere teologie te verstaan omdat so baie gedagtelyne terugvoer na hierdie eeuse teologie. Bultmann en Tillich bv. is moeilik verstaanbaar sonder kennis van die teologie van Schleiermacher. En terwyl die naam van Schleiermacher nou genoem is, sou $u$ die teologiese basis van hierdie voordrag miskien as Schleiermacheriaans kon bestempel. Ek het vantevore immers te kenne gegee dat ek sekere ervarings uit die verlede onder woorde wil bring. Formeel kom dit presies ooreen met Schleiermacher se teologiese beskouing, want teologie was vir hom die onder woorde bring van godsdienstige gevoelens en ervarings, die allerindividueelste ekspressie van die allerindividueelste religieuse ervaring.

2(ii). Omdat ek egter nie van Schleiermacherianisme beskuldig wil wees nie, haas ek my na die tweede en eintlike manier waarop ons blik in die verlede teologiese karakter kan verkry. Karl Barth het een keer ' $n$ baie belangrike boek geskrywe oor die Protestantse teologie in die 19de eeu. In ' $n$ inleidende hoofstuk het hy die uitbeelding en verstaan van ' $n$ stuk teologiese geskiedenis 'n teologiese taak genoem en een en ander daaroor opgemerk wat ook vir ons nou ter sake is. Dit kom in hoofsaak daarop neer dat ' $n$ mens nie bloot ' $n$ beskouer van ' $n$ gebeurtenis kan wees nie, maar dat jy dit eers verstaan as jy self daarby betrokke raak, as deur die geskiedenis iets self met of vir jou gebeur. Teologie kan alleen diegene verstaan wat self daadwerklik met die teologiese probleem besig is. Barth beklemtoon dit dat al die ou teoloë leef. Hulle het elkeen voor ons in hulle eie tyd ter wille van dieselfde kerklike taak dieselfde besinning gelewer wat vandag van ons geëis word. Sonder verantwoording teenoor hulle kan ons ons diens vandag nie lewer nie. Wat hierdie m.i. nog altyd grootste teoloog sedert die reformasie oor en oor beklemtoon en waarteen hy onophoudelik waarsku, is die teologiese roes van selfingenomenheid en selfvoldaanheid oor ' $n$ eie teologiese bevinding. So ' $n$ teologiese selfversekerdheid vergelyk hy met iemand wat alleen skaak speel en elke ander teoloog ' $n$ wit of swart figuur op sy skaakbord maak. Dit gaan in die geskiedenis van die teologie om die waarheid van God en nie om menslike verworvenhede nie en daarom moet ons ons teenoor die manne van die verlede stel nie in die houding van alles-reeds-weet nie, maar in die houding van bereidheid om weer iets nuuts van hulle te verneem. Laat ons ons so tans stel teenoor elkeen van die viermanskap van die ou fakulteit op wie ons blik vandag gerig is.

\section{Person, werk, vraag.}

3(i). Die lede van die ou fakulteit bied wat persoonlikheid en geaardheid betref, 'n ryke verskeidenheid. Prof. Greyvenstein, beginner van die opleiding en in wie se huis "Van der Hoff" gestig is, was ' $n$ forse gestalte met iets vorsteliks in sy voorkoms en optrede. As dit van iemand waar was, dan gewis van hom, dat die ö̈ die 
vensters van die siel is. Elkeen wat met hom te doene gehad het, moes ongetwyfeld onder die indruk van sy persoonlikheid gekom het. Vanweë sy ireniese geaardheid, sy simpatieke omgang en die warmte van persoonlikheid, was hy van vroeg af deur sy studente gedoop tot ou Vader of ou Vadertjie. Hy was miskien die mees sprekende verpersoonliking van die lewensideaal van die teologiese rigting waartoe hy saam met die twee ander ouer lede van die fakulteit behoort het, nl. die ou etiesie, wat in die gees van Ritschl die klem laat val het op die opbou van die sedelike persoonlikheid. In die sedelike beroepstrou het Ritschl die vervulling van die voorbeeld van Christus gesien. Hoe 'n mens ook mag verskil van Ritschl met sy klem op die versoening wat as verwerklikte lewensideaal vir hom die gevolg van die regverdiging is, en al moet 'n mens ook toegee dat hy die teologie te veel veretiseer het en die sedelike daad te hoog aangeslaan het, was die draers van daardie teologie tog ' $n$ galery van hoogstaande en stylvolle vroom persoonlikhede wat in mens met afguns vervul. Die teologie waartoe ook prof. Greyvenstein behoort het, het erns gemaak met die vraag van die lewe van die gelowige. Die vraag wat van prof. Greyvenstein kom tot ons vandag is hoe dit gesteld is met vroomheid van lewe van die gelowige in die wêreld, of geloof en lewe, belydenis en lewe met mekaar ooreenstem.

3(ii). In voorkoms en temperament was prof. S. P. Engelbrecht die teenoorgestelde van prof. Greyvenstein. Hy was haastig, rusteloos en impulsief van geaardheid. Oom Fanie, soos sy studente hom genoem het, het in elke nuwe teologiese student wat op Pretoria geland het in die eerste plek 'n toekomstige bouer van die Ned. Herv. Kerk van Afrika gesien. Niemand het ooit meer as hy persoonlike belangstelling in die studente getoon nie. Sy ywer vir alles wat met die Herv. Kerk in verband staan, was aansteeklik. Hy het hom so met die Herv. Kerk vereenselwig dat alles wat met die kerk gebeur het aanvaar is asof dit op hom gemik was, en alles wat met hom gebeur het is beskou as teen die kerk gemik. Sy lewe lank was hy 'n verbete vegter vir die belange van die kerk en as daar een ding is wat hy sy studente wou leer, dan was dit dat lidmaatskap van die kerk van Christus beteken liefde vir die geinstitueerde kerk waarvan 'n mens lidmaat is. Liefde vir sy geskiedenis, vir sy gebruike, vir sy gewoontes. Die vraag wat van oom Fanie na ons toe kom vandag is daar die ontsettende belangrike vraag na die kerkwees van die kerk. En nou wil ek die uitdagende . werklikheid nie probeer ontwyk deur te vlug in 'n teoretisering oor wat die wese van die kerk is nie. Daar is ' $n$ paar direkte vrae waarop ons elkeen 'n antwoord sal moet gee, soos

(i) word ons nie so verblind deur die glorie van die Ned. Herv. kerk en leef ons nie dalk so na binne gekeer, druk besig 
om te stabiliseer, te organiseer en te preserveer dat ons nie opmerk hoe geweldig ons besig is om te stagneer nie?

(ii) is dit ons werklik erns met die eenheid van die kerk of praat ons maar slegs mee terwyl dit by ons 'n uitgemaakte saak is dat die historiese status quo gehandhaaf moet word nie?

(iii) het ons nie so ryk en verryk geword nie en het die predikantebestaan nie so 'n welversekerde bestaan geword met so ' $n$ weelderige versorging dat ons weinig van die onrus openbaar oor die feit van toenemende onkerksheid en ongeloof?

(iv) Prof. Gemser het een keer die opmerking gemaak by 'n sekere feesgeleentheid i.v.m. oom Fanie dat in mens telkens in Almanak en Hervormer die woorde S.P.E. onder artikels sien. Hy het gesê dit sou kon beteken: sy plesier eerste of sy party eerste. Op die party kom ek straks terug en die plesier laat ek daar en ek vra of dit ook van ons waar is dat S.P.E. volgens Gemser indertyd beteken het: sy plig eerste. Kry ons in ons gemeentes werklike dieptebearbeiding?

3(iii). Terwyl die naam van prof. Gemser nou genoem is, kan ons gerus na hom hoe oorskakel. Wanneer 'n mens aan B. Gemser dink, dink jy onmiddellik aan strenge gedissiplineerdheid, stiptelike noukeurigheid en pynlike deeglikheid. Hy was in man van die wetenskap vir wie studie geen vermoeiing van die vlees was nie. Dit word vertel dat hy selfs tydens sy bootreise na Europa wanneer hy met vakansie gegaan het, nooit nagelaat het om elke dag 'n bepaalde getal ure te studeer nie. Sy wetenskaplike prestasies is dan ook genoegsaam bewys dat harde studie nie vrugteloos is vir die wetenskap van die kerk nie. Sy koms na Suid-Afrika het nie slegs vir ons kerk en die teologiese gehalte van sy predikante ontsaglik veel beteken nie, maar vir die bevordering van die studie van die Semitiese tale in ons land. As daar een uitstaande saak is wat hy sy studente geleer het, was dit liefde vir die studie. Hy herinner die kerk dat sonder die beoefening van die teologiese arbeid die prediking van die kerk, en daarmee die kerk self kwyn, want die kerk ontstaan, bestaan en bestaan voort deur die regte prediking van die evangelie.

Die uitstaande vraag van oom Bennie aan die kerk is: hoe staan dit met die teologiese arbeid? Nou weet ek gaan ons dadelik antwoord deur te wys op die groot getal doktorale studente en die doktorandi van die afgelope jare. Die vraag is egter nie of ons tydelik studeer vir grade nie, maar of ons gedissiplineerd studeer, elke dag. elke week elke jaar, of studie deel van ons lewe geword het. 
3(iv). Die laaste lid van die ou viermanskap was so anders, so heeltemal anders as die ander. Teologies moet hy by die dialektiese groep geplaas word, hoewel hy nooit 'n grondige studie van Barth gemaak het nie. Die godsdiensfilosofie van Brunner veral het hy deeglik geken en van hom ook geleer dat teologie van die kerk slegs teologie van die Woord kan wees. Hoewel die jongste van die vier lede van die ou fakulteit, was hy die enigste wat in die tradisie van die ou boervolk baie vroeg in sy lewe 'n baard gekweek het. Die gebied onderkant die ore was egter baie duidelik nie so vrugbaar as die bokant nie. Sy boersheid het ook verder daaruit geblyk dat hy probeer woon het in gebiede waar ' $n$ mens nog ' $n$ melkkoei en ' $n$ hoender kon aanhou. Tot in sy ouderdom het hy niks meer geniet as om naby die Afrikaanse grond te lewe nie. Die Afrikaanse bodem die Afrikaanse saak in al sy aspekte van kultuur en politiek, was sy groot belangstelling. Oom H.P. het ons geleer dat godsdiens en kultuur onlosmaaklik met mekaar verbind is. Die godsdiens as geloofsbetrekking tussen skepsel en Skepper word geleef deur die mens as kultuurwese. Daardie kultuur word nie opgehef deur die geloof nie, maar dit word hervorm deurdat dit 'n kultuurlewe word wat in gehoorsaamheid aan Gods Woord gelewe word. Prof. Wolmarans het ons geleer dat ' $n$ gelowige kerkmens nooit los van sy volk en vreemd teenoor sy vaderland hoef te leef nie. Waar prof. rircyvenstein liefde tot die Heer van die kerk opgewek het, prof. Engelbrecht liefde vir die liggaam van die Heer, prof. Gemser liefde vir die Woord van die Heer, wou prof. Wolmarans liefde wek vir die nasionale, geografiese en kulturele ruimte waarbinne die kerk van die Here lewe.

Wie met land en volk te doen het, kry met die politiek te doen. Die vraag wat van prof. Wolmarans tot die kerk vandag kom, wil ek formuleer as die politieke vraag en dit is in die huidige tydsgewrig miskien die mees aktuele vraag. Die problematiek rondom die politieke vraag wil ek uitdruk in twee formulerings: die eerste is, die kerk in die politiek. Dit lyk vir my die regte en normale, want dit wil uitdrukking gee aan die verantwoordelikheid van die kerk teenoor die politiek. Die getuienis van die kerk en sy reformerende verteenwoordiging van die Woord van God is dringend noodsaaklik. Wanneer die formulering egter die politiek in die kerk word, tree die ontaarding en die abnormale in en word dit gevaarlik vir die kerk. Dan gaan dit nie meer om die kerstening van die politiek nie, maar om die verpolitisering van die kerk. Dis hier waar my groot onrus lê en waaraan ek verplig is om uiting te gee in verantwoordelikheid teenoor ons kerk. Ek doen dit met die hoop en in die vertroue dat ons die moed en die verantwoordelikheidsgevoel sal hê teenoor evangelie en kerk om as volwasse kerkmense die saak met beheersdheid uit te praat. Niks sal my groter vreugde verskaf as my 
onrus ongegrond blyk te wees nie. Omdat dit 'n delikate saak is wil ek probeer om myself so versigtig as moontlik uit te druk en wil ek my onrus onder twee hoofde ter sprake bring: 'n aktuele en 'n prinsipiële.

Wat i) betref die volgende:

* Verbeel ek my maar net, of is dit 'n feit dat 'n georganiseerde politieke blok besig is om in ons geledere gevorm te word?

** Verbeel ek my maar net, of is dit 'n feit dat 'n politieke verdagmaking besig is om ons daadkrag te verlam?

*** Is dit 'n spontane en normale verskynsel dat Van der Hoff die laaste paar jare feitlik in sy geheel beheers word deur 'n politieke rigting wat nie die rigting is wat die algemene is in die kerk as geheel nie?

**** Is dit normaal en gesond dat politiek-gekleurde koukusse die verkiesing van jaarliks besture voorafgaan?

Wat ii) betref, lê my onrus nog dieper en word ek gedwing om effens radikaler te praat. As ek die algemene politieke situasie in ons land reg sien, dan het ons die sentrale regerende party en die erkende opposisie met twee vleuels ter linker en ter regter syde wat op die oog af diametraal teenoormekaar staan. Die linkse ken ons as die uiters liberale met 'n kenmerkende oordrewe liefde vir die swartman. Die regse ken ons as die uiters konserwatiewe met 'n kenmerkende liefde vir die sentimente van die Afrikaanssprekende deel van die blanke bevolking. Maar nou kom die diep verontrustende vraag by my op of links en regs mekaar tog nie onbewus en onbedoel in 'n gemeenskaplike punt ontmoet nie, wat 'n mens nergens in hulle program van beginsels geformuleer sal vind nie, maar wat tog diep verskuild in die gees van albei lewe as 'n verborge motief wat ek baie versigtig en tot sy minimum gereduseer 'n tikkie van haat wil noem nie, die een ten opsigte van 'n sekere deel van ons blanke bevolking, die ander ten opsigte van die swartman in ons land nie. In die jongste formulering van die geloofsleer waarin ons ons lidmate en toekomstige lidmate onderrig, lees ek egter heel tereg dat haat die wese van die sonde is. Maar hierdie ou mens is deur Christus gekruisig en daarom leef ons in die kerk in die liefde van Christus wat dring. In die lig van dit alles wil dit vir my lyk of die oomblik van geloofsbeslissing vir ons aangebreek het.

4. Slot.

Die gevoel oormeester my byna om verskoning te vra aan die einde van my voordrag wat so ons'kuldig begin het en so skokkend geëindig het. Ek wil egter nie apologeties wees nie. Die blik op die lede van die ou fakulteit het nou eenmaal hierdie vrae by my opgewek en ek is dankbaar dat ek hulle nou aan u ook kon oordra. 